\title{
Finding Home:
}

\section{Developing a Sense of Belonging Through Service-Learning}

Siqing "Erica" He

Rutgers University

\section{Recommended Citation:}

He, S. (2019). Finding home: Developing a sense of belonging through service-learning. International Journal of Research on Service-Learning and Community Engagement, 7(1), Article 4. 


\title{
Finding Home: Developing a Sense of Belonging through Service-Learning
}

\author{
Siqing "Erica" He \\ Rutgers University
}

\begin{abstract}
The study discussed in this article explored how 1.25-generation Asian immigrant high school students negotiated their sense of belonging as they participated in an afterschool service-learning-based program and made sense of their experiences. Having immigrated during their teenage years, 1.25 -generation immigrant students may face more exacerbated isolation from the mainstream community due to language and cultural barriers compared to youth who immigrated at younger ages. Findings from the study show that participants' experiences with service-learning-based pedagogy positively impacted their sense of belonging to the local community as they increased their knowledge about the community, rebuilt their confidence through formal leadership roles, and formed relational bonds with community members they met at the service-learning projects. The findings suggest therefore that participants broadened their sense of inclusion and belonging even if they had recently joined the space or community.
\end{abstract}

Keywords: 1.25 generation, afterschool programs, Asian immigrant youth, English language learners, sense of belonging

After I back to China, I kind of feel I cannot fit into China anymore because the way I think and it's different, like when I talk to my cousins, we just think differently. ... But I cannot say I belong to America, because I feel like it is still not my native language or native nation.

- Jenny (pseudonym), four years in the United States

In the preceding epigraph, Jenny, reflecting on her recent trip to China, expressed confusion about her identity and an unsettled sense of belonging as she interacted with her cousins. While China was her home, it no longer elicited the type of feelings she had before. Surprisingly, she did not feel she belonged to the United States, either; instead, she identified with Bay Point (pseudonym), the local neighborhood where she lived and attended high school. There, she felt that people were more willing to talk to her and did not see her as odd. This was in stark contrast to her undergraduate experiences at a four-year public university, where she tried with limited success to become friends with her native English-speaking peers. They would exchange pleasantries and be respectful to each other, but she felt none of them really wanted to get to know her. By contrast, in Bay Point, even non-Chinese people were interested in getting to know her and thought it was "cool" that she was Chinese. These feelings and experiences, reflecting an atypical sense of belonging, are common themes among immigrant youth as they are often marginalized or unwelcomed in schools due to their being viewed as non-native English-speaking racial minorities in the U.S. system of social stratification (Abu El-Haj, 2015; Lee, 2009; Nguyen, 2012).

This article discusses a study that aimed to show the relevance and role of a service-learning (SL)based afterschool program in the development of a sense of belonging among 1.25-generation Asian immigrant youth (i.e., those who immigrate between the ages of 13 and 17 years old). While immigrant youth's sense of belonging to the United States is primarily mediated by their socialization in schoolswhere they have the most frequent contact with U.S. institutional culture (Baquedano-López \& Mangual Figueroa, 2012) - afterschool program sites can also facilitate connections to their new school community and neighborhood by offering a more flexible experiential approach to learning (Tokunaga \& Huang, 2016; Wong, 2010). The following research question guided this study: How does participation in an SLbased afterschool program influence Asian immigrant youth's view of "home" and sense of belonging? 


\section{Literature Review}

\section{Defining Service-Learning}

Service-learning, an experiential pedagogical method used commonly in higher education, has become increasingly popular in K-12 and afterschool co-curricular settings as well. While there is no precise definition, and although implementation can "look" different from site to site, SL generally consists of a "community service action tied to learning goals and ongoing reflection about the experience" (Mitchell, 2008, p. 50) extending beyond the traditional classroom setting. Differing from community service, which focuses on benefiting the recipient of the service, SL aims to "equally benefit the provider and the recipient of the service as well as to ensure equal focus on both the service being provided and the learning that is occurring" (Furco, 1996, p. 5). The learning in SL is often associated with the curriculum in traditional academic courses, but scholars have noted that co-curricular SL, such as alternative spring break or the Bonner Scholar Program, has defined learning goals and structured reflection activities that draw upon students' academic knowledge or professional skills without an in-class academic component (Griswold, 2013; Howard, 2001; Keen \& Hall, 2009). This broader definition of SL puts more emphasis on integrating structured learning goals (academic or non-academic) and reflection, which is often missing from volunteerism or community-service programs.

\section{Studies on Service-Learning with Students of Color}

Many qualitative and quantitative evaluations of SL-based courses and programs have shown that the SL approach benefits students academically, socially, and civically at both the postsecondary and K-12 levels (Astin, Vogelgesang, Ikeda, \& Yee, 2000; Billig, 2000; Furco, 1996; Yeh, 2010). When SL is implemented among different racial groups, researchers have also found significant differences in outcomes and experiences when compared to SL implemented among White, middle-class students (Barrett \& Jenkins, 2018; Shadduck-Hernández, 2006; Swaminathan, 2005). Swaminathan (2005) showed that Black and Latinx students were inaccurately assumed to be juvenile delinquents performing mandatory community service by people at the service sites, while White students, in stark contrast, were praised for doing service. The impact of race needs to be researched further; however, Kahne, Crow, and Lee's (2013) study revealed that the SL pedagogical approach was mainly implemented among White, middle-class students and that low-income students of color did not have the same level of access. This limits the potential understanding of SL pedagogy in various contexts.

In addition to limited studies on students of color, Clifford (2017) argued that the unequal serverrecipient power dichotomy in SL reinforces the dynamic of exploitation by the privileged. Usually, the server is someone of higher status or privilege focused on gaining certain types of skills for academic credit from a recipient of lower status rather than on building solidarity with the recipient. This reinforces U.S. racial and class hierarchies since most SL programs are implemented among White, middle-class students. Mitchell (2008) recommended that the core of the SL process should comprise critical SL approaches that prioritize understanding and addressing structural inequalities rather than traditional SL approaches that reinforce hierarchies. The extent to which SL can achieve these outcomes must be further investigated, especially when implemented among students of color.

\subsection{5-Generation Asian Immigrant Youth}

Studies on Asian-American youth have frequently focused on stereotypes - for instance, model minority, honorary White, or perpetual foreigner-placed on them by hegemonic forces in U.S. society (Lee, 2009; Lee, Park, \& Wong, 2017; Ng, Lee, \& Pak, 2007). Most of the research participants in these previous studies have been 1.5- and second-generation Asian/Asian-American youth, whereas recent 1.25generation immigrant students are often understudied. (Children born in the United States to immigrant parents are second-generation, and those immigrating between the ages of 6 and 12 years old are classified as 1.5-generation [Rumbaut, 2004, p. 3].) Compared to second-generation youth born in the 
United States, 1.25-generation immigrant youth may be influenced by or have differing perspectives on race, identity, and citizenship as their lives are often situated across multiple social, cultural, linguistic, and national contexts due to their history of living in another country during their childhood and early adolescence (Nguyen, 2012; Park, 2011; Talmy, 2009).

Language is often a marker of otherness. When 1.25-generation immigrant students arrive in the United States, their schools frequently label them as English language learners (ELLs) and place them in English as a Second Language (ESL) programs until they pass the district's English proficiency test. The 1.25-generation immigrant students often have lower socioeconomic outcomes and a weaker sense of belonging to the mainstream community compared to 1.5- or second-generation students due to steeper language and cultural barriers (Myers, Xin, \& Amon, 2009; Portes \& Rivas, 2011; Rumbaut, 2004). Cherng, Turney, and Kao (2014) found that first- to second-generation immigrant youth of color were less likely than their native-born White peers to report having or socializing with friends from school. Concurrently, extracurricular clubs or sports-mechanisms that support social interaction and friendships - can be underutilized by ELLs as teachers push them to participate in academic or language tutoring to improve low test scores and grades (Carhill-Poza, 2014).

EMPOWER, the research site for this study, provided a unique opportunity to expand the understanding of SL's impact in a co-curricular setting among recent 1.25-generation Asian immigrant students from working-class families. In terms of privilege and status, these immigrant students are usually the recipients in SL projects due to language, race, and class, but EMPOWER defied such deficit perspectives and placed them in server roles. Furthermore, Pak (2018) found that SL pedagogy helped undergraduate heritage students of Spanish strengthen their sense of belonging at a predominately White institution, where they often felt isolated. The current ethnographic study builds on previous studies by elucidating pedagogical practices occurring at a co-curricular SL program and showing how 1.25generation students made sense of these experiences to shape their emergent sense of belonging in their new home.

\section{Sense of Belonging as a Theoretical Framework}

The migration-studies literature has a rich history of analyzing the macro-level socioeconomic and educational outcomes of immigrants and their children to measure successful assimilation into mainstream U.S. society (Portes, Fernández-Kelly, \& Haller, 2009); however, micro-level factors of assimilation, such as feelings of belonging and identity, are often overlooked and understudied. Antonsich (2010) provided an analytical framework for the concept of belonging: "Belonging should be analyzed both as a personal, intimate feeling of being 'at home' in a place (place-belongingness) and as a discursive resource which constructs, claims, justifies, or resists forms of socio-spatial inclusion/exclusion (politics of belonging)" (p. 1). He argued that researchers need to analyze both the place-belongingness and the politics of belonging so the analysis does not become solely focused on a decontextualized individualism or an all-encompassing socializing discourse.

\section{Place-Belongingness}

Place-belongingness refers to the feelings of being "at home," alluding to intimate ideas of safety, comfort, and relaxation; however, the feelings do not have to be located where one lives. In modern societies, people have a range of groups they can choose to identify with, or feel "at home" in, rather than having only top-down assigned forms of membership and belonging (Guibernau, 2013). According to a bottom-up approach, individuals can become part of a group or organization by learning its practices, norms, and language through a dynamic and social process. Relational factors, such as personal and social ties between individuals, also contribute to feelings of place-belongingness.

Relational ties, depending on whether they are strong or weak, reflect emotional investments and desires for attachments as individuals often are "caught within wanting to belong, wanting to become, a process that is fueled by yearning rather than positing of identity as a stable state" (Yuval- Davis, 2006, p. 
202). Baumeister and Leary's (1995) "belongingness hypothesis" postulated that individuals have an innate human need to belong and for frequent physical interactions that are long-lasting, positive, stable, and significant — that is, filled with concern and caring - generating a sense of (group) belonging.

\section{Politics of Belonging}

The politics of belonging comprises the discourses and practices that maintain "boundaries [separating] the world population into 'us' and 'them"' (Yuval-Davis, 2006, p. 204) as individuals decide whether a new person they meet stands inside or outside the boundary of their nation or communities of belonging. Since there is a boundary, the politics of belonging usually involves two opposite sides: One side "seeks" belonging and the other side, which has the power, "grants" belonging (Antonsich, 2010). The boundary between the seeker and granter can occur on the everyday level between business owners and their migrant employees (Yuval-Davis, Wemyss, \& Cassidy, 2018) or on the societal level between different religions and national citizenships (Yuval-Davis, 2011). Practices, such as labels on ID cards or clothing styles, signal the boundary explicitly, but the boundary can also be reinforced discursively through language from a common "us" perspective or a foreign "them" standpoint.

\section{Study Setting and Research Methods}

\section{Program and Community Context}

EMPOWER focuses on college readiness, leadership development, and civic engagement through SLbased pedagogy and is part of a larger nonprofit organization called HES (pseudonym). EMPOWER's SL curriculum is based on the RMC Research Corporation's (2009) K-12 Service-Learning Project Planning Toolkit, in which learning goals and reflection activities are incorporated into each step of the servicelearning cycle (i.e., investigating, planning, implementing, reflecting, and celebrating). Typical SL projects include registering people to vote, beautifying parks, teaching young children the importance of recycling through art, and raising awareness about resources available to undocumented immigrants. In going through the SL cycle, the students in this study applied and strengthened their academic skills by conducting community surveys, performing background research on the chosen topic, doing community mapping, and giving presentations on their findings. Moreover, the youth organizer brought in guest speakers to educate students on the chosen topic for the SL project. The reflection components included group discussions about successes and challenges on a personal, organizational, and societal level, as well as journaling throughout the SL process.

At the time of the study, EMPOWER had two cohorts of ninth to 12th graders that met weekly for 1.5 hours, with approximately 20 to 25 students per cohort. Students were either ELLs, former ELL-labelled students who had tested out, or native English speakers, with approximately $90 \%$ of the students being 1.25- and 1.5-generation immigrants; the rest were second-generation. Most of the students were East Asian, predominantly of Chinese descent, with a few Latinx, South Asian, and African immigrant students as well. The students were from three different public high schools in Bay Point, a neighborhood in New York City. In the past 40 years, the racial demographic and linguistic landscape of Bay Point has changed significantly from a White, European-American, and English-speaking neighborhood to a mainly Asian neighborhood (i.e., immigrants from South Korea, Taiwan, and China). In 2017, the U.S. Census Bureau reported the racial breakdown of Bay Point to be approximately $52.6 \%$ Asian, $25.7 \%$ White, $17.4 \%$ Hispanic, and 2\% Black.

\section{Data Collection}

This article focuses on the 1.25-generation immigrant youth (referred to as focal students) within a larger ethnographic study of EMPOWER employing a grounded theory approach to data collection and analysis (Charmaz, 2014; Creswell, 2013). Data sources included field notes from weekly participant observations from February to June 2016, student journals, lesson plans, and audio-recorded and transcribed interviews 
from alumni $(n=7)$, current participants $(n=12)$, parents $(n=4)$, and adult staff members $(n=3)$. The student subjects were selected based on their age of immigration (favoring the 1.25 generation) and/or their level of involvement in the program as indicated by the youth organizer.

The definition of 1.25 generation in this study expands Rumbaut's (2004) narrower age criterion of 13-17 years to 12-18 years since some of the subjects were about to turn 13 when they immigrated; thus, these differences were considered negligible (see Table 1 for more detailed background information on focal students and adults). Some research subjects with high levels of program involvement were 1.5- or second-generation immigrants $(n=7)$ and therefore were not considered the central subjects of this study. However, gathering their experiences in the program helped deepen my analysis of the focal students.

Most interviews were conducted in English, though a few subjects felt more comfortable speaking in Mandarin; these latter interviews were translated into English by the author. Alumni interviews were conducted at various times during the data-collection period, while most of the adult staff, parent, and current participant interviews were conducted after the program ended in June 2016.

Table 1. Focal Students and Adults

\begin{tabular}{cccccc}
\hline Pseudonym & Gender & $\begin{array}{c}\text { Years in } \\
\text { U.S. }\end{array}$ & Age & Country of Birth/Ethnicity & $\begin{array}{c}\text { Status and Years in } \\
\text { EMPOWER }\end{array}$ \\
\hline Hui & F & 3 & 20 & China & Current, 2 years \\
Rebecca & F & 4 & 18 & China & Current, 1 year \\
Xiuying & F & 2 & 20 & China & Current, 2 years \\
Yong & M & 3 & 17 & China & Current, 1 year \\
MJ & F & 2 & 17 & Taiwan & Current, 2 years \\
Jun & M & 2 & 17 & China & Current, 1 year \\
Nancy & F & 4 & 16 & China, ethnically Korean & Current, 1 year \\
Jack & M & 4 & 20 & Vietnam & Alumni, 3 years \\
Jenny & F & 4 & 19 & China & Alumni, 2 years \\
Lijie & M & 6 & 18 & China & Alumni, 2 years \\
Michael & M & 8 & 21 & Hong Kong & Alumni, 4 years \\
Jessica & F & 6 & 20 & China, ethnically Korean & Alumni, 4 years \\
Vicky & F & -- & -- & China & Program Manager \\
Kevin & M & -- & -- & U.S., biracial Chinese/White & Youth Organizer \\
\hline
\end{tabular}

Note. All names are pseudonyms. Age, number of years in the United States, and years in EMPOWER were recorded at the time of the interview (February to June 2016). In addition to the 1.25-generation immigrant youth, I interviewed non-focal alumni and current participants who were 1.5- and second-generation immigrants $(\mathrm{n}=7)$ : Amy, Stephanie, Qiang, Wei, Mika, Cindy, Eric. I interviewed parents $(\mathrm{n}=4)$ : Fangai, Jian, Bingbing, Jie. I interviewed the former facilitator (2011-2013), Esther, who was the youth organizer when the alumni were members of EMPOWER. 


\section{Researcher Positionality}

I was the youth organizer at EMPOWER from 2013 to 2015. My previous role gave me special insights into the program and participant behaviors but could have also led me to overlook some themes. Thus, I reflexively analyzed my positionality and took the perspective of a novice during observations and memo writing. Additionally, because the youth may have seen me as an authority figure representing EMPOWER and felt uncomfortable being forthcoming, I discussed the rules of confidentiality with them at the beginning of the interviews. On the other hand, my previous role might have helped students feel more comfortable and open to sharing their perspectives since trust and rapport were already built into the relationship, which is an asset to robust interviews.

My identity as an educated, middle-class, Chinese-American woman who speaks English and conversational Mandarin influenced how the students related to me as an insider or outsider. There are nuances of Chinese culture that I - raised in the United States - am neither aware of nor understand. At the same time, because I speak Mandarin and am phenotypically East Asian, the students might have felt less self-conscious and more relaxed about their oral English as they often spoke of being nervous around native English speakers.

\section{Data Analysis}

Following a grounded theory approach, the coding scheme for this study employed an open-, axial-, and selective-coding process in an iterative format (Creswell, 2013). In the open-coding phase, I used codes derived from the research questions, analytical frameworks, and common words used by the research subjects (Charmaz, 2014), such as emotional attachments, belonging, home, teamwork, safety, communication problems, confidence, participation, and new experiences. After open coding, I performed axial coding to analyze how these codes were interconnected by writing memos focused on larger themes of belonging, community connection, identity, immigration, language, program features, and skill improvement. During the memo-writing process, the emic perspectives of students were triangulated with the weekly observations, facilitator interviews, and parent interviews as I documented the students' sense making and meaning making of their SL projects. After the axial coding, I used selective coding to build a theory that connected themes in the memos in a coherent framework as the students participated in EMPOWER and the SL projects. Throughout this iterative process, I revisited the initial data as new codes or themes emerged in the memo-writing process.

\section{Limitations}

One limitation of this study was that the research subjects self-selected by voluntarily joining EMPOWER, where they knew they would perform service projects and work on leadership skills. Therefore, they might have been predisposed to take up SL-based pedagogy. In addition, I focused on and interviewed the most engaged students at EMPOWER; thus, some of the less-engaged students might not have had the same outcomes expressed by the study participants. My weekly meeting observations indicated that some students were distracted during the teamwork activities or did not attend the service projects; therefore, their sense of belonging to the program and community might have been weaker.

\section{Findings}

Most of the immigrant students felt very comfortable and safe at EMPOWER because there was a culture of care, non-judgement, and openness compared to their regular academic classrooms. In school, they often felt invisible or scared to speak and participate since some classmates would laugh at their "accented" English. Jack expressed that he felt a lack of belonging in certain spaces:

Sometime when I am in the big group of people and they use some high level of English you know like SAT English, I feel like I'm left open. Like I'm left out sometime. ... Like I'm afraid that people they might not understand what I'm saying, and I hate it when people asking me to 
repeat it.

He felt distanced when people asked him to repeat what he said because it signaled that the listener did not understand his English even though they simply might not have heard him. For most of the 1.25generation immigrant youth, deficiencies in spoken English were at the forefront of their minds during daily interactions. Conversely, at EMPOWER and on their SL projects, the program exposed them to "scary" English-dominated spaces but affirmed their language abilities from a strengths-based perspective.

The findings that emerged from the data were divided into two sections: (a) developing a sense of belonging among the students within EMPOWER and (b) developing a sense of belonging to the local community. While examined here as discrete categories for clarity, I acknowledge that both contexts influenced each other in a fluid, non-linear process.

\section{Inclusivity and Service-Learning Pedagogy at EMPOWER}

"Everyone needs to speak up." One of the most apparent norms at EMPOWER was that "everyone needs to speak up." Mr. Kevin, the youth organizer, wanted everyone to be involved since "everyone should be learning, so if there are only a couple voices being heard or there's only, like, one or two people actually participating, then it defeats the purpose." Both Rebecca and Hui felt more passive or withdrawn in their academic classrooms but said they were more active at EMPOWER:

Rebecca: Before, I learned in school is like there always certain people in a class that talk that much, the other people are just quiet. They didn't get the chance to you know. Maybe say they don't want to speak, but in the program everyone get a chance. Everyone need to speak up.

Hui: And the group work [in school] like in the group there is always one person more activity, one person want to talk much. ... But in EMPOWER, you and Kevin say, "Everyone has to say something."

In the EMPOWER group discussions and presentations, the expectation that everyone speaks was notable for immigrant students. In English-dominant mainstream classroom discussions, immigrant students are often marginalized because they are afraid to speak due to deficit-based self-framings of their English skills or negative peer judgement, or because their teachers are not knowledgeable about how to incorporate former ELL-labelled students. By contrast, EMPOWER's inclusive culture of speaking up built bonds and feelings of safety and comfort among the student participants. When designing a new EMPOWER t-shirt, for instance, students indicated a sense of place-belongingness by using words such as home and smile to describe the program and drawing images (e.g., an umbrella) to show inclusivity. Mr. Kevin's student-centered pedagogy intentionally created a safe space for immigrant students to express their opinions and form new relational dynamics with peers without the anxiety of potentially being laughed at for their non-standard spoken English.

Building leadership and confidence. Many students in the study said their leadership skills improved through their participation in EMPOWER and the SL curriculum. In the sessions, Mr. Kevin asked questions and waited one to two minutes in silence for a student to voluntarily answer. Sometimes he would say, "I'm not going to call on anybody. I want you guys to take the initiative and be leaders by volunteering to answer."

Moreover, there were multiple opportunities for students to take on formal leadership positions by facilitating icebreakers, acting as committee leaders for the SL projects, joining the core leadership team for the youth program, and serving as a moderator at EMPOWER's annual career conference. Although icebreakers might seem like trivial activities, students practiced their leadership and public-speaking skills as pairs of students created and led an icebreaker during every session and received feedback from their peers. Yong, a current participant who had been in the program for one year, said:

For icebreaker, I have to work with others. Other people, like then we got to talk about our icebreaker and explain it to others. If you are the host, you have to explain the rules. I think that is 
one example of leadership skills.

This placed the two facilitating students in an active role rather than the passive role of listener that they often experienced in mainstream classrooms. Leading the icebreaker, Yong looked nervous as he stuttered with his English and had trouble keeping his gaze on the audience. Afterwards, he received constructive feedback from peers such as the need to be more energized and to smile. This is a valuable experience for high school students, especially immigrant students, because they often do not have an opportunity to take on active leadership roles and then reflect on those roles through peer feedback. For students who were uncomfortable with their oral English skills, Mr. Kevin assigned them as translators, speaking the icebreaker directions in Mandarin; therefore, they were still participating as leaders even if they were not as proficient in English.

In addition to formal leadership roles, the SL curriculum positioned the students as leaders within their local community as they planned their SL projects. The students conducted surveys, community mapping, or online research on issues related to the environment, health, and immigration before deciding on their SL projects. Often, ELLs are the recipients in SL projects in which native English speakers provide English tutoring (Pak, 2018; Shadduck-Hernández, 2006), thereby perpetuating unequal societal power dynamics (Clifford, 2017), but at EMPOWER, they were the servers. The student participants were the voices of their community, sharing ideas about how to create positive change and directing the path of the SL project for community improvement. The SL pedagogy not only asked them to participate verbally in the programmatic space but also discursively framed them as citizens of Bay Point trying to make the community a better place. During a community-mapping exercise related to the environment, students were asked to draw their community from memory. Some students drew places closer to where they lived (i.e., in Bay Point or another adjacent neighborhood), and some chose the Bay Point neighborhood where they went to school. The guest speaker remarked that students drew their school, the library, supermarkets, and parks, which was good, but there was a lot of white space; therefore, the speaker recommended that students pay more attention to their surroundings as they walked through the neighborhood. The SL curriculum's framing of the students pushed them to conceptually and discursively integrate themselves as citizens of Bay Point even if they did not have U.S. citizenship or had lived in the United States for only a couple of years. Bay Point was not only a place where they went to school, but a "home" or a place of belonging that they wanted to understand and improve.

Furthermore, the students' confidence grew as they learned and practiced speaking up, sharing ideas, giving presentations, leading teams, and advocating for themselves. Xiuying, who had been in the United States for only two years, felt she learned to be more confident through the program and would be taking that with her to college:

Xiuying: I think when we talk about our projects, we just give ideas, but sometimes for you not confidence, you just stay and listen to others. You can't learn, you need to show your idea to others and talk about this idea and even you will get a lot of feedback and they will give you how to do this better or this is not good. If you just stay there and not show, nobody will know what you want or what do you think. You will feel boring in this program. If you show yourself, you will join this, you will learn more.

Erica: But how did you learn to be more confident? Can you give me a specific example of, like, how you gained more confidence?

Xiuying: Because we need to speak public, like we need to stand in front and speak. So you must confidence; you must know, "Oh, I can do it." That is one thing. And we need to know, "You can do it." Even though I can share my idea, and my idea is good, some people will not like this idea.

Having been in the United States for only two years, Xiuying was apprehensive at first about contributing and was more comfortable in the passive role of listening. Eventually, given her feelings of place-belongingness or home at EMPOWER, she realized she needed to become more active and express her opinions and ideas about the SL projects, thus increasing her confidence. This was a powerful 
learning outcome as many of the 1.25-generation immigrant students spoke about how they had lost their confidence after coming to the United States. Even if some of them learned English before immigrating, they realized that the English they learned was frequently incomprehensible to native English speakers in school. Their sense of belonging to the program - feelings of comfort and safety-helped them step out of their comfort zones and actively participate in ways they were afraid of doing in academic classrooms. The formal leadership roles, opportunities to express their voices, and SL curriculum that positioned them as servers helped the 1.25-generation students regain some of their former confidence.

\section{Connecting to the Community Through Service-Learning}

Increased knowledge and engagement in the community. Most of students in the study felt they had improved their understanding of the local community and increased their exposure to new experiences through the SL projects. Before joining the program, they tended to return to their homes and rarely ventured out to explore or understand their new neighborhood. EMPOWER exposed them to new places as they participated in college visits, job-shadowing events at various companies, and the SL projects, which took place in libraries, public parks, or the local YMCA. This was exciting to them as they had never been to these sites before, oftentimes because their parents did not have time to take them due to their working-class jobs or because they were afraid to go to such places by themselves. When Jessica, an alumnus of EMPOWER, first joined the program, she saw it as a way to do something more exciting than being home alone and to gain a better understanding of U.S. culture and the educational system:

I also feel like that kind of interesting because [EMPOWER] do like a lot of activity in there and like icebreaker and at first make me feel college more, and that was pretty interesting to me, too, because my mom was working and ... my dad was still in California, so like I couldn't have a lot of chance to go somewhere new. But like whenever there is like a trip or like more session, we could go outside of Bay Point a lot; so like I was feel more interesting with it.

Other EMPOWER participants expressed similar sentiments. Their parents' social and cultural capital was limited to non-mainstream sectors of the United States. However, through the SL curriculum, EMPOWER exposed them to mainstream organizations and policies. During the environmental SL project, for instance, the youth organizer collaborated with the local parks and recreation department to bring in guest speakers, who educated the students about the importance of protecting trees and the need to keep parks public in urban spaces. Many of the students had not known that this type of organization existed or how to get in touch with the organization. Without the collaboration with the department, the students would not have known that such an agency existed.

Through increased societal knowledge and exposure to new places, the students felt more engaged in the community. As stated earlier, besides going to school or work, most of the students spent a significant amount of time at home. They did not attend many community events, but through their connection with EMPOWER, they became more aware of local community events at which they could volunteer or work. For Hui, her shyness and her being in the United States for only three years hindered her from going places by herself. However, she felt less afraid about going to new places in her community when activities at those places were organized or advertised by EMPOWER:

I do these things that connect to the community; I feel I know more about the community. Like before I didn't know like many things like many events or activities about the community, and now because I am doing the voter registration like each Saturday they have event or something. We go there and do the voter registration. So I going there I know they have this event and they help people with this thing or that things.

Without this experience, Hui could have remained scared about participating in community events, but through EMPOWER's structured SL projects and field trips, she saw the benefits of being social and engaged with the community beyond just walking to school. 
There is a boundary between the mainstream sectors of society and marginalized groups such as recent immigrants; therefore, they are often unaware of certain knowledge and public resources. When I asked participants' parents about the U.S. secondary or postsecondary system, they did not seem to know much about it and told me that they trusted that the school and teachers would inform their children about what to do, especially since they did not go to college in their home country. Some schools did keep students informed, but for the focal youth in this study, they went to a public school that employed only one college counselor for approximately 1,200 students. Because of the severe gap in resources, EMPOWER's SL-based pedagogy helped the 1.25-generation students cross social boundaries to increase their knowledge of mainstream agencies and public resources available in U.S. society by exposing them to new places and facilitating their participation in these spaces.

Creating memories and relational bonds. When students in the study recounted the SL projects they remembered or enjoyed the most, they often referenced ones in which they interacted with new people. Some remembered the SL project in which they created a game for the children in the park while their peers painted the jungle gym. Some remembered the community presentation about resources for undocumented immigrants because approximately 30 people attended, which made some students feel they were making an impact. Stephanie felt especially appreciated when passersby would say "Thank you" because they usually do not say anything to the students. In her interview, she said:

There was somebody who walking by the park, and he actually said "Thank you." He was the first person to say thank you, and nobody else said thank you, so I was happy. Like there were people in the park, they saw us, but they wouldn't say anything, but that guy said "Thank you."

These interactions with either service recipients or passersby impacted the students since they helped create a bond with local community members with whom they would not otherwise have had the opportunity to interact. Rebecca, a current participant, remarked that, as teenagers, the students interacted mainly with their peers, teachers, and family; so it was interesting and exciting for her to meet new kinds of people through the SL projects at EMPOWER.

While the relational bonds established during the SL projects might be interpreted as temporary or weak because they happened only once (Baumeister \& Leary, 1995), I argue that it at least created the foundation for a sense of place-belongingness (Antonsich, 2010) to the local community. The 1.25generation immigrant students were able to cross the discursive boundary of "us" versus "them" (YuvalDavis, 2006) by serving community members or volunteering alongside professionals from mainstream companies who were invited to the SL projects. They might never speak to those people again, but in the moments during the SL projects, they experienced positive social interactions with strangers - making their new surroundings a little less scary.

Moreover, the SL projects created fond memories they can recount to others or themselves as they pass by the places where the SL projects took place. While talking about how the park beautification SL project helped him connect to the community, Lijie, an alumnus of EMPOWER, said:

When I see those things we did in the park, my connection appeared again. I suddenly saw myself doing a part of a job; so at that moment, every time when I go to that park or pass that park, a feeling coming from it.

Instead of viewing the park as a nondescript place that he passed by, he now associated it with the images and feelings he had during the SL projects as they cleaned the park, played with children, and painted the jungle gym.

Such interactions and memories are especially impactful in the development of a sense of belonging among 1.25-generation immigrant students since they will have more to talk about from their lives in the United States. Ms. Vicky, the program manager of EMPOWER, remarked that she did not think the students had a sense of belonging in the United States:

I think through my interaction with my students, we talk about lots of like cultures or life back in China, and then they can tell me a lot of things about that. But when we talk about life in the U.S., 
a lot of it is an "I don't know" answer.

Conversations with "a lot of ... 'I don't know answers"” signal a lack of commonalities, thus making the conversations short and reinforcing discursive borders; however, Ms. Vicky noticed that the students had longer conversations when drawing from their life experiences in their origin countries. This points to the value of SL pedagogy in creating memories and experiences. Rather than being isolated and spending all of their non-school time at home or communicating with friends from their origin country, some of the immigrant students participating in EMPOWER's SL projects met new people, went to new places, and created new memories they can draw upon to cross discursive boundaries when conversing and when building new friendships.

\section{Discussion and Implications}

Immigrant students' sense of belonging to their new home is a process of "becoming" as they try to fit into their new communities and social structures. Based on Antonsich's (2010) politics of belonging concept, the findings of this study indicate that the SL-based pedagogy at EMPOWER "granted" the 1.25generation students access to mainstream U.S. society and a national imaginary as they were "seeking" those aspects in their new life in the United States. Although schools are the primary sites of socialization for immigrant students into U.S. culture, peers and adult staff do not always welcome or value the background of immigrant students. The 1.25-generation immigrant students in this study were very selfconscious about their English-language skills and their ability to communicate with others, especially native English speakers. If other people could not understand their English, they automatically felt embarrassed and distant.

The SL-based pedagogy at EMPOWER creates structured opportunities (e.g., meeting banking professionals at the park beautification SL project or registering strangers to vote) for students to participate in and confront social interactions in which they normally felt nervous because of perceived inferiority in their oral English abilities. These types of experiences potentially impact immigrant students' emerging sense of belonging in the United States. For immigrant students like Jenny, deficitoriented stereotypes from U.S. society, such as "unknowledgeable immigrant" or "bad English speaker," frame them as individuals who do not belong and who are outside the boundary of the U.S. national imaginariness. By contrast, EMPOWER offers a strength-oriented identity for 1.25-generation immigrants, such as "Bay Point citizen" (and "potentially U.S. citizen"), as their multinational lives are not viewed as a hindrance to civic engagement in the United States; rather, their ideas about improving the local community are seen as valued and needed.

EMPOWER's SL pedagogy framed the immigrant students in the study as part of the community, even if they had been in the United States for only a few years, because the youth organizer constantly asked them about how they could improve "their" community. They were made to feel like they belonged even if they only recently joined the space or community. EMPOWER placed them in server, rather than recipient, roles, which is uncommon for immigrant students; thus, their success in implementing the SL projects increased their personal confidence as they viewed themselves from a strengths-based perspective rather than a deficit-oriented viewpoint. Being the server in the server-recipient relationship, their language marginalization was less prioritized compared to the ideas and value they brought to the service project. Furthermore, because belonging is a process rather than a stable entity (Yuval-Davis, 2006), the students were slowly given the tools to cross the discursive boundaries between "us" and "them" through the increased knowledge they had gained about the community, increased feelings of confidence, and relational bonds they formed with new people they met through the SL projects. Thus, they crossed the discursive border by creating memories or participating in spaces that are supposedly outside the boundary where they belong, thereby broadening their sense of inclusion and belonging.

This study highlights the potential of SL-based pedagogy to positively influence a sense of belonging among immigrant students in a co-curricular context. As the study indicates, 1.25-generation immigrant students of color are often marginalized in U.S. society and made to feel less capable due to perceived deficits in language skills or knowledge of cultural norms. The SL approach allows them to take on server 
12 | International Journal of Research on Service-Learning and Community Engagement

roles that showcase their strengths in helping the local community and, through this process, helps them feel more engaged in the community, thus shaping their sense of belonging to their new home.

\section{References}

Abu El-Haj, T. R. (2015). Unsettled belonging: Educating Palestinian American youth after 9/11. Chicago, IL: University of Chicago Press.

Antonsich, M. (2010). Searching for belonging: An analytical framework. Geography Compass, 4(6), 644-659.

Astin, A. W., Vogelgesang, L. J., Ikeda, E. K., \& Yee, J. A. (2000). How service learning affects students. Los Angeles CA: Higher Education Research Institute, UCLA.

Baquedano-López, P., \& Mangual Figueroa, A. (2012). Language socialization and immigration. In A. Duranti, E. Ochs, \& B. Schieffelin (Eds.), The handbook of language socialization (pp. 536-563). West Sussex, UK: Blackwell.

Barrett, M. S., \& Jenkins, I. (2018). Service-learning: A powerful pedagogy for promoting academic success among students of color. International Journal of Research on Service- Learning and Community Engagement, 6(1), 1-14.

Baumeister, R. F. \& Leary, M. R. (1995). Need to belong: Desire for interpersonal attachments as a fundamental human motivation. Psychological Bulletin, 117(3), 497-529.

Billig, S. H. (2000). Research on K-12 school-based service learning: The evidence builds. Phi Delta Kappan, 81(9), 658.

Carhill-Poza, A. (2014). "Spanish speakers" and "normal people." In J. Koyama \& M. Subramanian (Eds.), U.S. education in a world of migration: Implications for policy and practice (pp. 54-70). New York, NY: Routledge.

Charmaz, K. (2014). Constructing grounded theory. Thousand Oaks, CA: Sage.

Cherng, H., Turney, K., \& Kao, G. (2014). Less socially engaged? Participation in friendship and extracurricular activities among racial/ethnic minority and immigrant adolescents. Teachers College Record, 116(3), 1-28.

Clifford, J. (2017). Talking about service-learning: Product or process? Reciprocity or solidarity? Journal of Higher Education Outreach and Engagement, 21(4), 7-20.

Creswell, J. W. (2013). Qualitative inquiry and research design: Choosing among five approaches ( $3^{\text {rd }}$ 3rd ed.) Thousand Oaks, CA: Sage.

Furco, A., (1996). Is service-learning really better than community service? A study of high school service program outcomes. In A. Furco \& S. H. Billigs (Eds.), Service learning: The essence of the pedagogy (pp. 23-50). Greenwich, CT: Information Age.

Griswold, R. M. (2013). A mixed method study to measure outcomes from co-curricular service-learning experiences (Doctoral dissertation). Retrieved from http://hdl.handle.net/ $10657 / 1183$

Guibernau, M. (2013). Belonging: Solidarity and division in modern societies. Cambridge, UK: Polity.

Howard, J. (2001). Academic service-learning: Myths, challenges, and recommendations. Teaching Excellence: Toward the Best in the Academy, 12(2). Retrieved from https://podnetwork.org/content/uploads/V12-N2-Howard.pdf

Kahne, J., Crow, D., \& Lee, N. J. (2013). Different pedagogy, different politics: High school learning opportunities and youth political engagement. Political Psychology, 34(3), 419-441.

Keen, C., \& Hall, K. (2009). Engaging with difference matters: Longitudinal student outcomes of cocurricular service-learning programs. Journal of Higher Education, 80(1), 59-79.

Lee, S. J. (2009). Unraveling the "model minority" stereotype: Listening to Asian American youth (2nd ed.). New York, NY: Teachers College Press.

Lee, S. J., Park, E., \& Wong, J. H. S. (2017). Racialization, schooling, and becoming American: Asian 
American experiences. Educational Studies, 53(5), 492-510.

Mitchell, T. D. (2008). Traditional vs. critical service-learning: Engaging the literature to differentiate two models. Michigan Journal of Community Service Learning, 14(2), 50-65.

Myers, D., Xin, G., \& Amon, E. (2009). The gradient of immigrant age-at-arrival: Effects on socioeconomic outcomes in the U.S. International Migration Review, 43(1), 205-229.

Ng, J. C., Lee, S. S., \& Pak, Y. K. (2007). Contesting the model minority and perpetual foreigner stereotypes: A critical review of literature on Asian Americans in education. Review of Research in Education, 31(1), 95-130.

Nguyen, D. T. (2012). Vietnamese immigrant youth and citizenship: How race, ethnicity, and culture shape sense of belonging. El Paso, TX: LFB Scholarly Publishing.

Pak, C. S. (2018). Linking service-learning with sense of belonging: A culturally relevant pedagogy for heritage students of Spanish. Journal of Hispanic Higher Education, 17(1), 76-95.

Park, G. C. (2011). Becoming a "model minority": Acquisition, construction and enactment of American identity for Korean immigrant students. The Urban Review, 43(5), 620-635.

Portes, A., Fernández-Kelly, P., \& Haller, W. (2009). The adaptation of the immigrant second generation in America: A theoretical overview and recent evidence. Journal of Ethnic and Migration Studies, 35(7), 1077-1104.

Portes, A., \& Rivas, A. (2011). The adaptation of migrant children. The Future of Children, 21(1), 219246.

RMC Research Corporation. (2009). K-12 service-learning project planning toolkit. Scotts Valley, CA: National Service-Learning Clearinghouse. Retrieved from https://community.ksde.org/LinkClick.aspx?fileticket=kbpBbLMvts8\%3D\&tabid=4473

Rumbaut, R. G. (2004). Ages, life stages, and generational cohorts: Decomposing the immigrant first and second generations in the United States. International Migration Review, 38(3), 1160-1205.

Shadduck-Hernández, J. (2006). Here I am now! Critical ethnography and community service-learning with immigrant and refugee undergraduate students and youth. Ethnography and Education, 1(1), 67-86.

Swaminathan, R. (2005). "Whose school is it anyway?" Student voices in an urban classroom. In D. Butin (Ed.), Service-learning in higher education (pp. 25-43). New York, NY: Palgrave Macmillan.

Talmy, S. (2009). Forever FOB? Resisting and reproducing the Other in high school ESL. In A. Reyes \& A. Lo (Eds.), Beyond Yellow English: Toward a linguistic anthropology of Asian Pacific America (pp. 347-365). New York, NY: Oxford University Press.

Tokunaga, T., \& Huang, C. (2016). "I feel proud to be an immigrant": How a youth program supports ibasho creation for Chinese immigrant students in the U.S. In W. Ma \& G. Li (Eds.), Chineseheritage students in North American schools: Understanding hearts and minds beyond test scores (pp. 164-179). New York, NY: Routledge.

Wong, N. W. A. (2010). "Cuz they care about the people who goes there": The multiple roles of a community-based youth center in providing "youth (comm)unity" for low-income Chinese American youth. Urban Education, 45(5), 708-739. https://doi.org/10.1177/0042085909355766

Yeh, T. L. (2010). Service-learning and persistence of low-income, first-generation college students: An exploratory study. Michigan Journal of Community Service-learning, 16(2), 50-65.

Yuval-Davis, N. (2006). Belonging and the politics of belonging. Patterns of Prejudice, 40(3), 197-214.

Yuval-Davis, N. (2011). The politics of belonging: Intersectional contestations. Los Angeles, CA: Sage.

Yuval-Davis, N., Wemyss, G., \& Cassidy, K. (2018). Everyday bordering, belonging and the reorientation of British immigration legislation. Sociology, 52(2), 228-244. 
14 | International Journal of Research on Service-Learning and Community Engagement

\begin{abstract}
About the Author
Siqing "Erica" He is a doctoral candidate in the Department of Educational Theory, Policy, and Administration, Graduate School of Education, at Rutgers University-New Brunswick (NJ).

Correspondence concerning this article should be addressed to Siqing "Erica" He at erica.he@rutgers.edu.
\end{abstract}

